\title{
Profiling Scoliosis in Rett Syndrome
}

\author{
ALAN K. PERCY, HYE-SEUNG LEE, JEFFREY L. NEUL, JANE B. LANE, STEVEN A. SKINNER, SUZANNE P. GEERTS, \\ FRAN ANNESE, JOY GRAHAM, LAUREN MCNAIR, KATHLEEN J. MOTIL, JUDY O. BARRISH, AND DANIEL G. GLAZE
}

\begin{abstract}
Department of Pediatrics [A.K.P., J.B.L., S.P.G.], University of Alabama at Birmingham, Birmingham, Alabama 35294; Department of Pediatrics [H.-S.L.], University of South Florida, Tampa, Florida 33612; Department of Pediatrics [J.L.N., K.J.M., J.O.B., D.G.G.], Baylor College of Medicine, Houston, Texas 77079; Greenwood Genetic Center [S.A.S., F.A., J.G., L.M.], Greenwood, South Carolina 29646
\end{abstract}

\begin{abstract}
To understand scoliosis, related comorbidities, and phenotype-genotype correlations in individuals with Rett syndrome (RTT), the Rare Disease Clinical Research Network database for RTT was probed. Clinical evaluations included a detailed history and physical examination, comprehensive anthropometric measurements, and two quantitative measures of clinical status, Clinical Severity Scale (CSS) and motor-behavioral analysis (MBA). All data were exported to the Data Technology Coordinating Center (DTCC) at the University of South Florida. Scoliosis assessment was based on direct examination and curvature measurements by radiography (Cobb angle). Statistical analyses included univariate and multiple logistic regression models, adjusting for age at enrollment or mutation type. Scoliosis data were available from 554 classic RTT participants, mean age $=10$ y $(0-57$ y). Scoliosis was noted in $292(53 \%)$; mean age $=15$ y with scoliosis and 6 y without. Using multiple regression analysis, MBA severity score, later acquisition, loss or absent walking, and constipation were associated with scoliosis. Two common methyl-CpG-binding protein 2 (MECP2) mutations, R294X and $\mathrm{R} 306 \mathrm{C}$, had reduced risk for scoliosis. These findings corroborated previous reports on scoliosis and extended understanding of comorbidities, clinical severity, and relative risk reduction for specific mutations. Clinical trial design should account for scoliosis and related factors judiciously. (Pediatr Res 67: 435-439, 2010)
\end{abstract}

$\mathrm{R}^{\mathrm{c}}$ ett syndrome (RTT), a neurodevelopmental disorder identified primarily in females, is associated with a mutation in the methyl-CpG-binding protein 2 (MECP2) gene in 90$95 \%$ (1). The National Institutes of Health-funded Rare Disease Network for RTT is characterizing the clinical spectrum and natural history of RTT preparatory to the initiation of clinical trials. The major clinical issues associated with RTT include growth failure, scoliosis, gastrointestinal and breathing dysfunction, and stereotypic hand movements with poor fine motor skills, ambulation, and communication. Data for each clinical parameter are being analyzed. This report is concerned with scoliosis. The RTT consortium consists of three primary RTT centers (Baylor College of Medicine, Greenwood Genetic Center, and University of Alabama at Birmingham) and five traveling research sites across the US. Each evaluation includes a comprehensive assessment regarding clinical status and classification (classic versus atypical

Received August 31, 2009; accepted November 24, 2009.

Correspondence: Alan K. Percy, M.D., Department of Pediatrics, University of Alabama at Birmingham, 1530 3rd Avenue South, CIRC 320E, Birmingham, AL 35294; e-mail: apercy@uab.edu

Supported by the NIH (NCRR: RR019478/NICHD: HD38985), the International Rett Syndrome Foundation, and the Civitan International Research Center.
RTT), presence, and type of $M E C P 2$ mutations, and clinical severity. In advance of clinical trials, understanding the comorbidities such as scoliosis is critical.

Scoliosis is recognized as a common accompaniment of RTT. However, previous studies generally represent small sample sizes, parent completed questionnaires, and limited comparison by specific MECP2 mutations. The most comprehensive survey to date derives from the Australian Rett Syndrome Database (2). Scoliosis was present in $79 \%$ of 231 participants by age $13 \mathrm{y}$ and was positively related to aberrant development and lack of walking, but unrelated to loss of hand skills or age of onset of hand stereotypes. Scoliosis developed later in those with the common mutations R133C, R294X, and R306C, but significantly so for only R294X. Others reported frequencies ranging from 58 to $87 \%$ (3-6). The Swedish study (3) also noted a positive association between scoliosis and lack of walking. An earlier study from Australia revealed a 3-fold greater rate of surgery in individuals who never walked (Leonard H 1996 Rett syndrome in Australia (thesis) University of Western Australia Perth, Western Australia). In the UK study (5), scoliosis surgery was performed in the majority between ages 11 and $20 \mathrm{y}$.

The purpose of this study was to analyze the frequency of scoliosis among participants enrolled from March 2006 to March 2009, using data from 554 participants with classic RTT. This large cohort could allow us to extend the findings of previous studies and examine other clinical features and comorbidities associated with RTT.

\section{METHODS}

Participants. As part of the Rare Disease Clinical Research Network, the natural history study of RTT was organized in 2003. At present, $>700$ participants with RTT or with a mutation in the MECP2 gene have been enrolled. From this cohort, complete data are available for 689 participants, 586 of whom meet the consensus criteria for classic RTT.

Protocol. Each participant in this analysis was evaluated by members of the RTT consortium based at the Baylor College of Medicine, the Greenwood Genetic Center, or the University of Alabama at Birmingham using a common set of data collection instruments and the current consensus diagnostic criteria (7). Participants were classified as typical or atypical based on the application of these criteria and were entered into the database as such. Evaluations occurred twice annually through age $12 \mathrm{y}$ or annually beginning at age $13 \mathrm{y}$. A detailed history and physical examination and a comprehensive set of anthropometric measurements were obtained. In addition, two quantitative

\footnotetext{
Abbreviations: CSS, Clinical Severity Scale; MECP2, methyl-CpG-binding protein 2 gene; MBA, motor-behavioral analysis; RTT, Rett syndrome; P, having scoliosis
} 
measures of clinical status, the Clinical Severity Scale (CSS) and the motorbehavioral analysis (MBA) were completed (1). All data were then exported to the DTCC at the University of South Florida. This data repository was used for these analyses. With respect to the presence of scoliosis, initial assessment was based on direct examination with the participant seated in the vertical position and flexed forward at the waist to reveal the vertebral spines. In participants less than age $4 \mathrm{y}$ without evidence of scoliosis, this was the only assessment. After age $4 \mathrm{y}$, or when scoliosis was evident by direct examination, participants had radiographic assessment by their orthopedists. The resulting Cobb angle was recorded in the database.

Statistical analysis. Frequencies were reported for categorized outcomes and the means and SD were detailed with minimum and maximum values for continuously measured outcomes. The association between the prevalence of scoliosis and other clinical parameters was investigated using logistic regression models for having scoliosis $(\mathrm{P})$, adjusting for age in years at enrollment or mutation type. Each clinical parameter was first examined in a univariate model, and then a multiple regression model was set up by backward variable selection from the univariate analysis results. We also investigated the association between the prevalence of scoliosis and common mutation types from logistic regression models for $\mathrm{P}$, adjusting for age in years at the enrollment or significant clinical parameters included in the multiple models.

A $p<0.05$ was considered significant. SAS 9.1.3 (SAS institute, Cary, NC) was used for all statistical analyses.

The protocol and consent form were approved by the Institutional Review Boards of the Baylor College of Medicine, the Greenwood Genetic Center, and the University of Alabama at Birmingham.

\section{RESULTS}

Complete data were available for 689 participants, of whom $586(85 \%)$ were female with classic RTT, $79(11 \%)$ with atypical RTT, and 24 (4\%) without clinical features of RTT. A MECP2 mutation was identified in 555/586 (95\%) in classic RTT, 53/79 (67\%) in atypical RTT, and 24/24 (100\%) in participants without clinical features of RTT. For the entire cohort, scoliosis was noted in 292/586 (50\%) with classic RTT, 31/79 (39\%) with atypical RTT, and 5/24 (21\%) in participants without clinical features of RTT. Focusing on the 586 classic RTT participants, we analyzed the prevalence of scoliosis with $M E C P 2$ mutation type and clinical parameters collected at enrollment. As shown in Table 1, 555/586 (95\%) participants with classic RTT had a detectable MECP2 mutation including 348 (59\%) with one of the eight most common mutations (R106W, R133C, T158M, R168X, R255X, R270X, R294X, and R306C), 37 (6.3\%) with 3' frameshift deletions, $50(8.5 \%)$ with large deletions, and $111(19 \%)$ with other mutations. In addition, 554/586 (95\%) participants reported whether they had scoliosis at enrollment; 292/554 (53\%) participants were confirmed to have scoliosis.

The mean age for classic RTT participants was $10 \mathrm{y}$ ranging from $<1$ to $57 \mathrm{y} ; 38 \%$ were under $5 \mathrm{y}$ and $28 \%$ were greater than $13 \mathrm{y}$; this older age group comprised $45 \%$ of participants with scoliosis and only $9 \%$ of those without scoliosis. The mean age was $15 \mathrm{y}$ for those with scoliosis and $6 \mathrm{y}$ for those lacking scoliosis participants, producing a significant between-group age difference $(p<0.0001$ using two sample $t$ test). In as much as nearly $40 \%$ of the cohort were <age $5 \mathrm{y}$; this frequency distribution is not surprising. For those participants age 16 y or older, $85 \%$ reported scoliosis.

We examined overall clinical severity scores on both the CSS and MBA, BMI z-scores using CDC standardization, absent or lost ability to sit or walk, hand use, seizures, bone fractures, constipation, peripheral vasoconstriction, age at regression, and head growth and compared these with the presence or absence of scoliosis. As age or mutation type could confound the relationship between scoliosis and each clinical parameter, two models, one adjusting for age alone, the other adjusting for both age and mutation type were used to investigate the association. As shown in Table 2, the increased prevalence of scoliosis was significantly associated with higher overall clinical severity scores on both the CSS and MBA, delayed acquisition, loss, or absence of sitting and walking, occurrence of seizures, constipation, peripheral vasoconstriction, and poor head growth after adjusting for age and mutation type. In our cohort, no participant with scoliosis reported acquired and maintained hand use, whereas $6 \%$ of those without scoliosis had preservation of acquired and conserved hand use. Including all significant clinical parameters in the model, we constructed the multiple logistic regression model with backward variable selection. In this model, severity score on MBA, later acquisition, loss, or absence of walking, and occurrence of constipation retained the positive association with scoliosis (Table 3).

Examination of specific mutations showed that R133C, R294X, and R306C are significantly associated with de-

Table 1. Mutation distribution and scoliosis occurrence in 586 participants with classic RTT

\begin{tabular}{|c|c|c|c|c|c|c|}
\hline \multirow[b]{2}{*}{$M E C P 2$ mutation } & \multicolumn{2}{|c|}{ All } & \multicolumn{2}{|c|}{ Scoliosis } & \multicolumn{2}{|c|}{ No scoliosis } \\
\hline & $N(\%)$ & Age* & $N(\%)$ & Age & $N(\%)$ & Age \\
\hline R106W & $20(10)$ & $13.7 \pm 13.0(1,36)$ & $10(50)$ & $22.7 \pm 12.7(5,36)$ & $8(40)$ & $2.9 \pm 1.2(1,5)$ \\
\hline $\mathrm{R} 133 \mathrm{C}$ & $22(4)$ & $8.6 \pm 7.6(2,36)$ & $7(32)$ & $9.9 \pm 3.4(6,17)$ & $15(68)$ & $8.1 \pm 9.0(2,36)$ \\
\hline $\mathrm{T} 158 \mathrm{M}$ & $70(12)$ & $10.8 \pm 7.5(2,33)$ & $39(56)$ & $14.6 \pm 7.0(2,33)$ & $26(37)$ & $4.8 \pm 3.8(2,19)$ \\
\hline R168X & $63(11)$ & $9.2 \pm 9.5(1,47)$ & $31(49)$ & $14.2 \pm 10.9(3,47)$ & $29(46)$ & $4.0 \pm 3.7(1,17)$ \\
\hline $\mathrm{R} 255 \mathrm{X}$ & $61(10)$ & $7.6 \pm 6.2(0,30)$ & $28(46)$ & $11.0 \pm 6.2(5,30)$ & $30(49)$ & $4.6 \pm 4.8(0,19)$ \\
\hline R270X & $34(6)$ & $10.7 \pm 11.6(2,57)$ & $19(56)$ & $14.7 \pm 13.5(3,57)$ & $12(35)$ & $3.9 \pm 2.5(2,11)$ \\
\hline R294X & $37(6)$ & $14.8 \pm 8.1(3,34)$ & $15(41)$ & $19.3 \pm 8.0(6,34)$ & $21(57)$ & $12.0 \pm 6.8(3,30)$ \\
\hline $\mathrm{R} 306 \mathrm{C}$ & $41(7)$ & $10.0 \pm 9.3(2,46)$ & $12(29)$ & $17.1 \pm 13.3(4,46)$ & $25(61)$ & $6.6 \pm 4.4(2,23)$ \\
\hline C-terminal deletions & $37(6)$ & $11.2 \pm 9.4(2,44)$ & $22(59)$ & $13.3 \pm 9.0(3,44)$ & $14(38)$ & $8.5 \pm 9.8(2,38)$ \\
\hline Large deletions & $50(9)$ & $9.8 \pm 7.2(1,26)$ & $29(58)$ & $13.3 \pm 6.9(3,26)$ & $18(36)$ & $4.6 \pm 4.3(1,20)$ \\
\hline Other mutations & $111(19)$ & $9.8 \pm 8.3(0,44)$ & $61(55)$ & $13.7 \pm 7.6(2,33)$ & $47(42)$ & $4.8 \pm 6.4(0,44)$ \\
\hline No mutation & $31(5)$ & $14.5 \pm 8.7(2,31)$ & $14(45)$ & $19.7 \pm 8.0(4,31)$ & $13(42)$ & $9.2 \pm 5.8(2,20)$ \\
\hline$>1$ mutation & $9(2)$ & $7.3 \pm 6.4(1,19)$ & $5(56)$ & $10.8 \pm 6.7(3,19)$ & $4(44)$ & $3.0 \pm 1.8(1,5)$ \\
\hline Total & $586(100)$ & $10.4 \pm 8.7(0,57)$ & $292(50)$ & $14.5 \pm 9.0(2,57)$ & $262(45)$ & $5.95 \pm 6.0(0,44)$ \\
\hline
\end{tabular}

The values are represented as mean $\pm \mathrm{SD}$ (minimum, maximum).

* Age at enrollment. 
Table 2. Relationship between scoliosis and clinical parameters: univariate

\begin{tabular}{|c|c|c|c|c|}
\hline \multirow[b]{2}{*}{ Clinical parameter } & \multicolumn{2}{|c|}{ Scoliosis* } & \multirow[b]{2}{*}{ Model $1 \dagger$} & \multirow[b]{2}{*}{ Model $2 \dagger$} \\
\hline & Yes $(N=292)$ & No $(N=262)$ & & \\
\hline Clinical severity & $26.5 \pm 7.0(9,43)$ & $19.9 \pm 5.8(7,36)$ & $1.20(1.15,1.24)$ & $1.19(1.14,1.24)$ \\
\hline Motor-behavioral assessment & $55.9 \pm 12.9(27,89)$ & $44.1 \pm 12.6(10,81)$ & $1.07(1.05,1.09)$ & $1.06(1.05,1.08)$ \\
\hline BMI & $-0.83 \pm 1.82(-7.9,2.6)$ & $-0.40 \pm 1.61(-5.4,3.6)$ & $0.93(0.83,1.05)$ & $0.91(0.81,1.29)$ \\
\hline \multicolumn{5}{|l|}{ Sitting } \\
\hline$\leq 8 \mathrm{mo}$ & $141(48 \%)$ & $142(54 \%)$ & Ref & Ref \\
\hline$>8$ mo or lost or never & $151(52 \%)$ & $120(46 \%)$ & $1.72(1.16,2.56)$ & $1.65(1.08,2.53)$ \\
\hline \multicolumn{5}{|l|}{ Walking } \\
\hline$<18$ mo/apraxic gait & $55(19 \%)$ & $81(31 \%)$ & Ref & Ref \\
\hline$\geq 18$ mo or lost or never & $237(81 \%)$ & $181(69 \%)$ & $4.68(2.72,8.04)$ & $3.76(2.11,6.70)$ \\
\hline \multicolumn{5}{|l|}{ Seizures } \\
\hline Absent & $160(55 \%)$ & $198(76 \%)$ & Ref & Ref \\
\hline Any & $132(45 \%)$ & $64(24 \%)$ & $1.71(1.13,2.60)$ & $1.77(1.13,2.75)$ \\
\hline \multicolumn{5}{|l|}{ Bone fractures } \\
\hline No & $255(87 \%)$ & $246(94 \%)$ & Ref & \\
\hline Yes & $37(13 \%)$ & $16(6 \%)$ & $1.27(0.62,2.61)$ & $1.47(0.69,3.12)$ \\
\hline \multicolumn{5}{|l|}{ Constipation } \\
\hline No & $32(11 \%)$ & $82(31 \%)$ & Ref & Ref \\
\hline Yes & $260(89 \%)$ & $180(69 \%)$ & $2.92(1.73,4.95)$ & $2.89(1.67,5.02)$ \\
\hline \multicolumn{5}{|l|}{ Peripheral vasoconstriction } \\
\hline None & $87(30 \%)$ & $119(45 \%)$ & Ref & Ref \\
\hline Any & $205(70 \%)$ & $143(55 \%)$ & $1.67(1.11,2.52)$ & $1.56(1.01,2.40)$ \\
\hline \multicolumn{5}{|l|}{ Age at regression } \\
\hline$>30 \mathrm{mo}$ & $28(10 \%)$ & $23(9 \%)$ & Ref & Ref \\
\hline 18 to $30 \mathrm{mo}$ & $121(41 \%)$ & $126(48 \%)$ & $1.17(0.55,2.48)$ & $1.15(0.51,2.57)$ \\
\hline 12 to $18 \mathrm{mo}$ & $111(38 \%)$ & $90(34 \%)$ & $2.31(1.07,4.98)$ & $1.98(0.87,4.50)$ \\
\hline 6 to $12 \mathrm{mo}$ & $22(8 \%)$ & $19(7 \%)$ & $1.91(0.70,5.21)$ & $1.59(0.55,4.57)$ \\
\hline$<6 \mathrm{mo}$ & $10(10)$ & $4(2 \%)$ & $3.09(0.70,13.72)$ & $2.60(0.52,13.11)$ \\
\hline \multicolumn{5}{|l|}{ Head growth } \\
\hline None to minimal & $60(21 \%)$ & $65(25 \%)$ & Ref & Ref \\
\hline Deceleration & $232(79 \%)$ & $196(75 \%)$ & $1.80(1.11,2.92)$ & $1.92(1.14,3.22)$ \\
\hline
\end{tabular}

* Mean $\pm \mathrm{SD}$ (minimum, maximum) or $N(\%)$.

$\dagger \mathrm{OR}(95 \% \mathrm{CI})$.

Model 1, logistic regression model for $\mathrm{P}$ (having scoliosis $=1$ ) adjusting for age; model 2, logistic regression model for $\mathrm{P}($ having scoliosis $=1)$ adjusting for age and mutation type.

Table 3. Significant clinical parameters from multiple logistic regression model for $P$ (having scoliosis) $=1$ adjusting for age and mutation type (backward variable selection)

\begin{tabular}{lcc}
\hline Clinical parameter & OR $(95 \% \mathrm{CI})$ & $p$ \\
\hline $\begin{array}{c}\text { Motor-behavioral } \\
\text { assessment }\end{array}$ & $1.05(1.03,1.07)$ & $<0.0001$ \\
Walking & & \\
$\quad \begin{array}{c}\text { Acquired }<18 \mathrm{mo} / \\
\text { apraxic gait } \\
\text { Acquired } \geq 18 \mathrm{mo} \\
\quad \text { or lost or never }\end{array}$ & Ref & \\
$\begin{array}{c}\text { Constipation } \\
\text { No }\end{array}$ & $2.29(1.24,4.22)$ & 0.0079 \\
Yes & & \\
& Ref & \\
& $2.08(1.15,3.76)$ & 0.0153 \\
\hline
\end{tabular}

creased risk of $\mathrm{P}$ compared with all other mutations after adjusting for age (Table 4), but only for R294X and R306C after additionally adjusting for the three significant clinical parameters: MBA, walking, and constipation. However, note that $\mathrm{R} 133 \mathrm{C}$ has lower frequency than $\mathrm{R} 306 \mathrm{C}$ ( $4 \%$ versus $7 \%$ ) but higher prevalence of scoliosis (32\% versus 29\%) in this sample. Among participants with one of the eight common mutation types, we further examined the effect of decreasing risk of scoliosis in R294X. Participants with T158M, R168X, $\mathrm{R} 255 \mathrm{X}$, and R270X had significantly higher risk of developing scoliosis than those with R294X in both models (Table 5).
Scoliosis surgery was performed in 70/554 (13\%) participants reporting whether or not they had scoliosis and was less likely to have been done in individuals with R133C, R294X, and $\mathrm{R} 306 \mathrm{C}$ mutations. The mean age $( \pm \mathrm{SD})$ at surgery was $12 \mathrm{y}( \pm 3 \mathrm{y})$, and the median was also $12 \mathrm{y}$ (range 5-22 y). Individuals requiring surgery were much less likely to have acquired walking or to have retained previously acquired walking, namely, 65/71 (92\%) compared with 6/71 (8\%) who had acquired walking before surgery and retained walking afterward.

\section{DISCUSSION}

Scoliosis is common in RTT and increases in frequency with age through puberty. In this study, $85 \%$ of participants who were 16 y of age or greater had some degree of scoliosis. As such, scoliosis represents a significant comorbidity that should be monitored carefully, especially during the formative years and during adolescence when idiopathic scoliosis may also worsen.

This report corroborates previous findings on scoliosis frequency from Europe and Australia (3-6) and extends our understanding of interactions with specific comorbidities and overall clinical severity. Predictors of scoliosis include the type and location of the specific $M E C P 2$ mutation, overall 
Table 4. Relationship between common mutation types and scoliosis

\begin{tabular}{|c|c|c|c|c|}
\hline & \multicolumn{2}{|c|}{ Model 1} & \multicolumn{2}{|c|}{ Model 2} \\
\hline & OR $(95 \% \mathrm{CI})$ & $p$ & OR $(95 \% \mathrm{CI})$ & $p$ \\
\hline \multicolumn{5}{|l|}{$M E C P 2$ mutation } \\
\hline Other mutations & Ref & & Ref & \\
\hline R106W & $0.80(0.21,3.11)$ & 0.7457 & $0.52(0.13,2.12)$ & 0.3584 \\
\hline $\mathrm{R} 133 \mathrm{C}$ & $0.31(0.10,0.98)$ & 0.0463 & $0.60(0.17,2.09)$ & 0.4245 \\
\hline $\mathrm{T} 158 \mathrm{M}$ & $0.92(0.43,1.94)$ & 0.823 & $0.80(0.35,1.80)$ & 0.585 \\
\hline R168X & $0.99(0.46,2.1)$ & 0.9739 & $0.90(0.40,2.01)$ & 0.7939 \\
\hline $\mathrm{R} 255 \mathrm{X}$ & $0.89(0.43,1.86)$ & 0.7567 & $0.72(0.33,1.59)$ & 0.4182 \\
\hline $\mathrm{R} 270 \mathrm{X}$ & $1.43(0.56,3.65)$ & 0.4514 & $1.16(0.40,3.35)$ & 0.7813 \\
\hline $\mathrm{R} 294 \mathrm{X}$ & $0.12(0.04,0.32)$ & $<0.0001$ & $0.16(0.05,0.46)$ & 0.0007 \\
\hline $\mathrm{R} 306 \mathrm{C}$ & $0.27(0.10,0.71)$ & 0.0079 & $0.32(0.11,0.94)$ & 0.0381 \\
\hline $\begin{array}{l}\text { C-terminal } \\
\text { deletions }\end{array}$ & $0.97(0.39,2.41)$ & 0.9543 & $0.88(0.32,2.41)$ & 0.8027 \\
\hline Large deletions & $1.19(0.52,2.74)$ & 0.6773 & $0.88(0.36,2.16)$ & 0.783 \\
\hline $\begin{array}{c}\text { Motor-behavioral } \\
\text { assessment }\end{array}$ & & & $1.05(1.03,1.07)$ & $<0.0001$ \\
\hline \multicolumn{5}{|l|}{ Walking } \\
\hline $\begin{array}{l}\text { Acquired }<18 \\
\text { mo/apraxic } \\
\text { gait }\end{array}$ & & & Ref & \\
\hline $\begin{array}{l}\text { Acquired } \geq 18 \\
\text { mo or lost } \\
\text { or never }\end{array}$ & & & $2.29(1.22,4.29)$ & 0.01 \\
\hline \multicolumn{5}{|l|}{ Constipation } \\
\hline No & & & Ref & \\
\hline Yes & & & $2.02(1.11,3.65)$ & 0.0211 \\
\hline
\end{tabular}

Model 1 , logistic regression model for $\mathrm{P}$ (having scoliosis $=1$ ) adjusting for age; model 2, logistic regression model for $\mathrm{P}$ (having scoliosis $=1$ ) adjusting for age and significant clinical parameters.

Table 5. Relationship between 8 common mutation types and scoliosis

\begin{tabular}{|c|c|c|c|c|}
\hline & \multicolumn{2}{|l|}{ Model 1} & \multicolumn{2}{|l|}{ Model 2} \\
\hline & OR (95\% CI) & $p$ & OR $(95 \% \mathrm{CI})$ & $p$ \\
\hline \multicolumn{5}{|l|}{$M E C P 2$ mutation } \\
\hline R294X & Ref & & Ref & \\
\hline R106W & $7.47(1.43,38.93)$ & 0.017 & $3.83(0.68,21.59)$ & 0.128 \\
\hline $\mathrm{R} 133 \mathrm{C}$ & $2.83(0.69,11.59)$ & 0.147 & $4.48(0.99,20.10)$ & 0.050 \\
\hline $\mathrm{T} 158 \mathrm{M}$ & $8.40(2.73,25.87)$ & 0.000 & $5.58(1.71,18.27)$ & 0.005 \\
\hline R168X & $9.18(2.83,29.81)$ & 0.000 & $6.59(1.89,22.92)$ & 0.003 \\
\hline $\mathrm{R} 255 \mathrm{X}$ & $8.21(2.61,25.83)$ & 0.000 & $5.16(1.54,17.30)$ & 0.008 \\
\hline R270X & $13.29(3.64,48.56)$ & $<0.0001$ & $8.28(2.02,33.91)$ & 0.003 \\
\hline $\mathrm{R} 306 \mathrm{C}$ & $2.42(0.68,8.66)$ & 0.173 & $2.11(0.53,8.44)$ & 0.290 \\
\hline $\begin{array}{c}\text { Motor-behavioral } \\
\text { assessment }\end{array}$ & & & $1.06(1.03,1.08)$ & $<0.0001$ \\
\hline \multicolumn{5}{|l|}{ Walking } \\
\hline $\begin{array}{l}\text { Acquired }<18 \\
\text { mo/apraxic } \\
\text { gait }\end{array}$ & & & Ref & \\
\hline $\begin{array}{l}\text { Acquired } \geq 18 \\
\text { mo or lost } \\
\text { or never }\end{array}$ & & & $2.58(1.16,5.71)$ & 0.020 \\
\hline \multicolumn{5}{|l|}{ Constipation } \\
\hline No & & & Ref & \\
\hline Yes & & & $1.30(0.61,2.78)$ & 0.500 \\
\hline
\end{tabular}

Model 1 , logistic regression model for $\mathrm{P}$ (having scoliosis $=1$ ) adjusting for age; model 2, logistic regression model for $\mathrm{P}$ (having scoliosis $=1$ ) adjusting for age and significant clinical parameters.

clinical severity, and absent or delayed development of motor skills. The recent report from Australia (2) did not detect an association between loss of hand skills and scoliosis frequency. Based on univariate analysis of our data, a positive association with scoliosis frequency was noted not only for hand use but also for other motor skills including sitting and walking, seizures, bone fractures, head growth, age at regression, peripheral vasoconstriction, and constipation. Refinement of this analysis using logistic regression with backward variable selection retained a significant association only for the total MBA score, delayed, lost, or absent walking, and the presence of constipation.

Although the association between poor walking skills and scoliosis seems predictable, the lack of correlation with age at regression and poor head growth is surprising. These are two of the consensus criteria for the diagnosis of RTT (7). Age at regression is a subjective determination based on parent perception. However, head circumference determinations are quantitative and should lack observer bias. The positive association with constipation likely reflects the increased frequency of motor impairments, particularly with respect to walking, but also with respect to clinical severity noted with the MBA. The MBA is a composite score that assesses motor skills at all levels including physical examination, behavioral and social assessment, and oromotor and respiratory parameters. As such, it represents a more comprehensive overall assessment than the more restricted CSS. In addition, the MBA does not consider age at regression and head growth, two elements of the CSS that are not associated with scoliosis in this study.

The relative risk reduction for scoliosis in individuals with the R294X and R306C mutations also extends the findings from the Australian database study that noted significance for the R294X mutation only. These results are likely to reflect our significantly larger pool of participants with these mutations that number several-fold more than in the Australian study (2). It is possible that R133C will also achieve significance as more individuals with this mutation are enrolled. Presently, this group is comprised of slightly $>50 \%$ of the R294X and R306C groups.

This study is strengthened by the large sample size and the distribution of participants by mutation type that is representative of mutation frequencies in RettBase (www. mecp2.chw.edu.au) and the North American database (8). However, the analyzed data are cross-sectional. On completion of the longitudinal phase of this study, analysis of prospectively collected data should provide an important complement to the current report.

Guidelines for the current management of scoliosis have been published recently (9). Substantive evidence is lacking regarding the efficacy of preventive measures for scoliosis. Nonetheless, the implementation of intervention strategies that could retard scoliosis progression is essential. These include effective positioning to provide optimal truncal support while upright and may include bracing and proper seating arrangements. A systematic study of such strategies should be considered.

The overall goal of the Rare Disease Clinical Research Network is to develop robust natural history information that will provide a credible baseline for impending clinical treatment trials. The development of fundamental therapeutic strategies for RTT is being pursued actively in the laboratory. As these therapeutic interventions are translated to individuals 
with RTT, clinical trial design should account for the presence of scoliosis and related factors judiciously.

Acknowledgments. We acknowledge the gracious participation and provision of information by families of the reported participants, the critical staff support of the International Rett Syndrome Foundation, and the expert guidance provided by Jeffrey Krischer, $\mathrm{PhD}$, and Rachel Richesson, $\mathrm{PhD}$, at the Data Technology Coordinating Center at the University of South Florida. Dr. Mary Lou Oster-Granite, Health Scientist Administrator at NICHD, provided invaluable guidance, support, and encouragement for this Rare Disease initiative.

\section{REFERENCES}

1. Neul JL, Fang P, Barrish J, Lane J, Caeg E, Smith EO, Zoghbi HY, Percy A, Glaze DG 2008 Specific mutations in methyl-CpG-binding protein 2 confer different severity in Rett syndrome. Neurology 70:1313-1321
2. Ager S, Fyfe S, Christodoulou J, Jacoby P, Schmitt L, Leonard H 2006 Predictors of scoliosis in Rett syndrome. J Child Neurol 21:809-813

3. Stokland E, Lidstrom J, Hagberg B 1993 Scoliosis in Rett syndrome. In: Hagberg B (ed) Rett Syndrome-Clinical \& Biological Aspects. Mac Keith Press, London, pp 61-71

4. Colvin L, Fyfe S, Leonard S, Schiavello T, Ellaway C, De Klerk N, Christodoulou J, Msall M, Leonard H 2003 Describing the phenotype in Rett syndrome using a population database. Arch Dis Child 88:38-43

5. Kerr AM, Webb P, Prescott RJ, Milne Y 2003 Results of surgery for scoliosis in Rett syndrome. J Child Neurol 18:703-708

6. Motil KJ, Ellis KJ, Barrish JO, Caeg E, Glaze DG 2008 Bone mineral content and bone mineral density are lower in older than in younger females with Rett syndrome. Pediatr Res 64:435-439

7. Hagberg B, Hanefeld F, Percy A, Skjeldal O 2002 An update on clinically applicable diagnostic criteria in Rett syndrome. Comments to Rett Syndrome Clinical Criteria Consensus Panel Satellite to European Paediatric Neurology Society Meeting, Baden Baden, Germany, 11 September 2001. Eur J Paediatr Neurol 6:293-297

8. Percy AK, Lane JB, Childers J, Skinner S, Annese F, Barrish J, Caeg E, Glaze DG, MacLeod P 2007 Rett syndrome: North American database. J Child Neurol 22:1338 1341

9. Downs J, Bergman A, Carter P, Anderson A, Palmer GM, Roye D, van Bosse H, Bebbington A, Larsson EL, Smith BG, Baikie G, Fyfe S, Leonard H 2009 Guidelines for management of scoliosis in Rett syndrome patients based on expert consensus and clinical evidence. Spine 34:E607-E617 